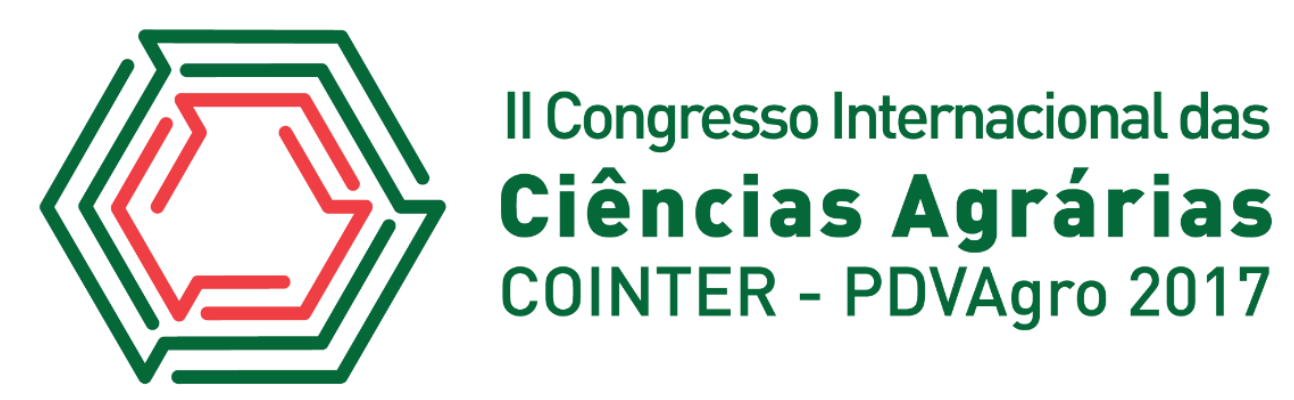

\title{
CULTIVO DE MANJERICAO VERDE EM FIBRA DE COCO FERTIIRRIGADO EM SOLUÇÃO NUTRITIVA
}

Jessilanne Plínia Barbosa de Medeiros $\operatorname{Costa}^{1}$; Ricardo Carlos Pereira da Silva ${ }^{2}$; Carla Jamile Xavier Cordeiro Silva ${ }^{3}$; Raiza Lopes da Silva ${ }^{4}$; Francisco de Assis de Oliveira ${ }^{5}$

\section{Introdução}

O manjericão (Ocimum basilicum L.) faz parte da família Lamiaceae, pode atingir até 1,0 m de altura, se destaca pelo uso na medicina tradicional ou popular em diversas propriedades. (BERTOLUCCI et al., 2008). A produção brasileira de manjericão é praticada principalmente por pequenos produtores e sua grande parte é destinada para comercialização de folhas verdes aromáticas (MAY et al., 2008). Entretanto existe algumas produçoes de óleos essenciais em maiores quantidades presentes do Nordeste.

Para preparação dos substratos a fibra coco pode ser utilizado no estágio verde ou seco e apresenta características desejáveis param um bom substrato, tais como alta retenção de umidade, resistência à degradação, uniformidade, ausência de patógenos e de ervas daninhas (OLIVEIRA et al., 2008, 2009;).

Neste sistema de culltivo a qualidade da solução nutritiva é fator primordial para se obter exito, pois todos os nutrientes necessarios para o crescimento das plantas são fornecidos via fertiirgação. Para o cultivo de manjericão são escassas recomendações de solução nutritiva, sendo que na maioria dos estudos desenvolvidos são utilizadas solucão nutritiva recomendada para folhosas (BIONE et al.,2014; FERNANDES et al.,2014).

Diante do exposto, objetivou-se com esse trabalho avaliar o crescimento de manjericao verde cultivado em fibra de coco e fertiirrigado em diferentes doses de solução nutritiva.

\footnotetext{
${ }^{1}$ Mestranda em Manejo de Solo e Agua, Ufersa, jessilannyplinia@ hotmail.com

${ }^{2}$ Doutorado em Agronomia, Ufpb, Ricardo_agro@hotmail.com

${ }^{3}$ Graduanda em Agronomia, Ufersa, carlajamile0808@gmail.com

${ }^{4}$ Engenheira Agrônoma, Ufersa, raf.lopes@hotmail.com

${ }^{5}$ Prof. Doutor, Ufersa, thikaoamigao@ufersa.edu.br
} 


\section{Metodologia}

O experimento foi conduzido em casa de vegetação da Universidade Federal Rural do Semiárido (UFERSA), localizada no município de Mossoró, RN. O delineamento utilizado foi o inteiramente casualizado, com cinco tratamentos e quatro repetições. Os tratamentos foram constituídos de cinco concentrações de soloução nutritiva (50, 75, 100, 125 e 150\%) da dose recomendada conforme Castellane \& Araújo (1994) para o cultivo hidroponico de folhosas. A solução padrão (100\%) apresentava a seguinte concentração de macronutrientes, em mg L-1, N=152; P=29, $\mathrm{K}=245 ; \mathrm{Ca}=20$ e $\mathrm{Mg}=32$, recomendada para a cultura da alface. No preparo das soluções, foi utilizada água proveniente do sistema de abastecimento do campus central da UFERSA, apresentando as seguintes características: $\mathrm{pH}=8,3 ; \mathrm{CE}=0,53 \mathrm{dS} \mathrm{m}^{-1} ; \mathrm{Ca}^{2+}=2,0 ; \mathrm{Mg}^{2+}=0,9 ; \mathrm{Na}^{+}=2,87 ; \mathrm{K}^{+}=0,4 ; \mathrm{HCO}_{3}^{-}$ =4,0; $\mathrm{CO}_{3}=0,2 ; \mathrm{Cl}^{-}=1,8\left(\mathrm{mmol}_{\mathrm{c}} \mathrm{L}^{-1}\right)$. Após o preparo de cada solução nutritiva determinou-se a condutividade elétrica, obtendo-se as salinidades de 0,$9 ; 1,5 ; 2,0 ; 2,6$ e 3,2 dS m m $^{-1}$, para as concentrações $50,75,100,125$ e $150 \%$, respectivamente.

As mudas de manjericão, cv. Verde, foram produzidas em bandejas de PVC, com substrato, composto por $100 \%$ de fibra de coco, de textura fina, sem adubação de base. As plantas foram coletadas aos 60 dias após o transplantio, e avaliadas quanto as seguintes variáveis: altura, diâmetro de caule, número de folhas, área foliar, massa seca de caule, massa seca de folhas, massa seca de raízes e massa seca total. Os dados obtidos foram submetidos a análise de variância e as variáveis que apresentaram resposta significativa aos tratamentos aplicados foram submetidas a análise de variância.

\section{Resultados e Discussões}

A altura das plantas foi afetada pelas soluções nutritivas, apresentando decréscimo linear de acordo com o aumento da concentração de nutrientes, reduzindo de $62,9 \mathrm{~cm}$ na concentração $50 \%$, para 47,4 cm na concentração $150 \%$, resultando em perda total de $24,6 \%$ (Figura 1A).

Foi observada resposta quadrática para a variável diâmetro de caule, ocorrendo aumento com incremento da concentração da solução nutritiva ate o nível $100 \%$ (5,7 mm), reduzindo a partir deste nível. Comparando-se esse valor com o obtido com a concentração a $50 \%(4,6 \mathrm{~mm})$ verifica-se aumento de 23,2\% (Figura 1C). 
O número de folha apresentou resposta linear e positiva ao aumento da concentração de nutrientes na solução nutritiva, observando-se que a cada aumento da dose nutritiva houve incremento na emissão foliar, aumentando de 150 folhas menor concentração (50\%) para 205 folhas na concentração 150\%, resultando em ganho de 36,7\%. (Figura 1B). Em mudas de pimentas foram observados resultados semelhantes, em que o número de folhas das mudas apresentou resposta quadrática conforme o aumento na concentração de nutrientes na solução nutritiva (PAGLIARINI et al., 2012; OLIVEIRA et al., 2014).

Para as variáveis área foliar e número de hastes ocorreram respostas semelhantes, apresentando aumento até a conentração de 92\%, com área foliar máxima de 1131,6 cm², e 21 hastes por planta. Desta forma, comparando-se aos valoes obtidos na concentração 50\% (947,4cm² e 17 hastes), ocorreram aumentos de 19,4\% para area foliar (Figura 1D) e 19,9\% para número de hastes (Figura 1E).

Também ocorreram respostas semelhantes para as variáveis massa seca de caule (MSC), massa seca de folhas (MSF), massa seca de raiz (MSR) e massa seca total (MST). Para todas estas variáveis, o aumento da concentração de nutrientes proporcionou incremento na massa seca até os níveis 79, 87, 92 e 89\%, com valores máximos de 4,7; 5,1; 1,6 e 11,9 g planta-1. Verificase ainda que, dentre as variaveis referentes ao acúmulo de massa seca, a maior resposta ocorreu para o sistema radicular, com ganho de $37,1 \%$ em relação ao valor obtido na concentração $50 \%$ $(1,1 \mathrm{~g})$, enquanto as massas secas de caule, folha e total apresentaram ganho de 10,3; 17,5 e 18,6\% respectivamente (Figura $1 \mathrm{~F}$ ).

De forma geral, verifica-se que, exceto para a variável número de hastes, todas as variáveis foram reduzidas quando as fertirrigações foram realizadas com solução nutritiva de maior concentração (150\%), tal comportamento pode ser explicado pelo efeito prejudicial da elevada condutividade elétrica desta solução nutritiva $\left(3,2 \mathrm{dS} \mathrm{m}^{-1}\right)$, confirmando os resultados apresentados por Bione et al. (2014) e Maia et al. (2017), trabalhando com manjericão em cultivo hidropônico NFT e em solo, respectivamente, os quais verificaram que o crescimento do manjericão é reduzido significativamente sob condições de estresse salino.

Figura 1. Altura (A), diâmetro do caule (B), número de folhas (C), área foliar (D), número de hastes (E) e massa seca (F) de manjericão cultivado em substrato e fertirrigadas com diferentes soluções nutritivas 
A.
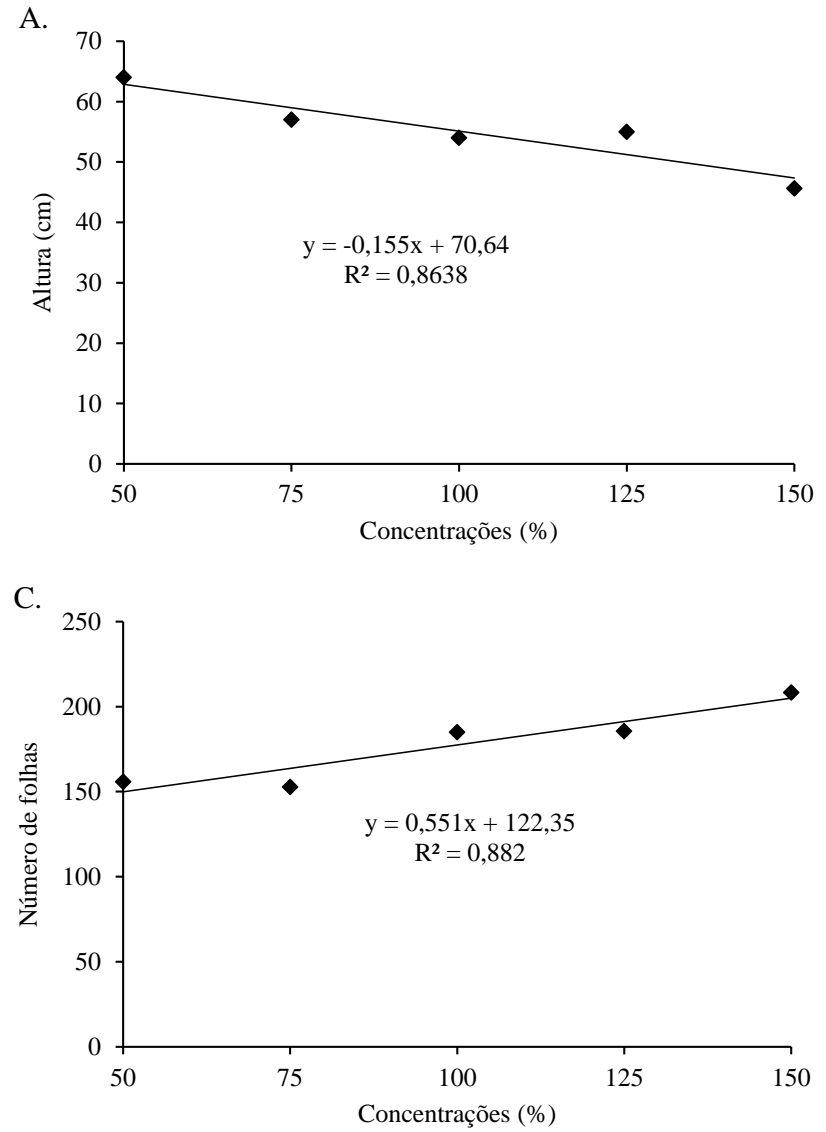

E.

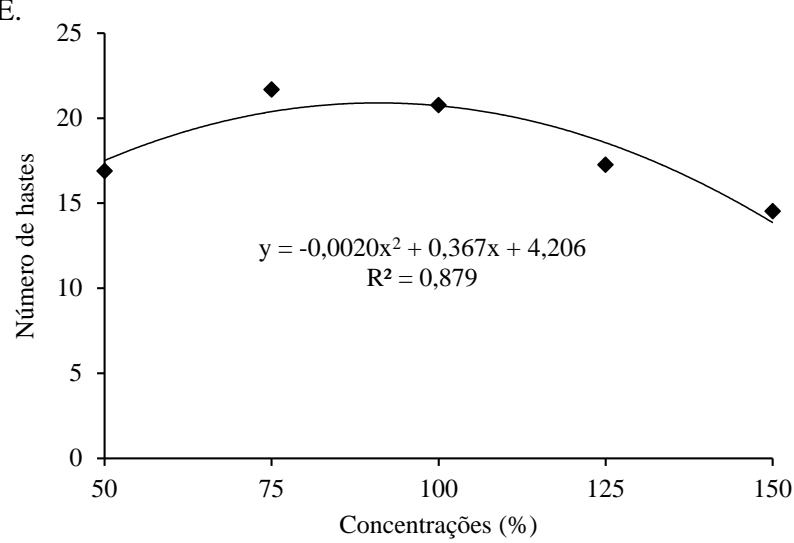

B.

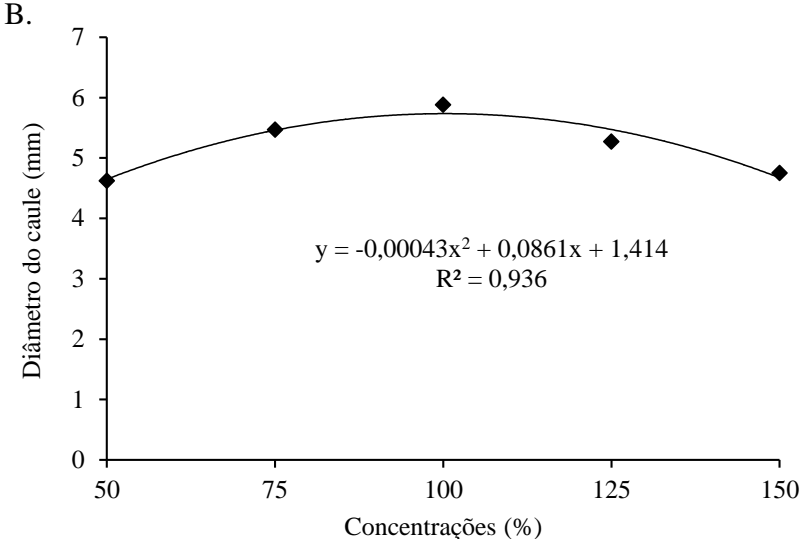

D.

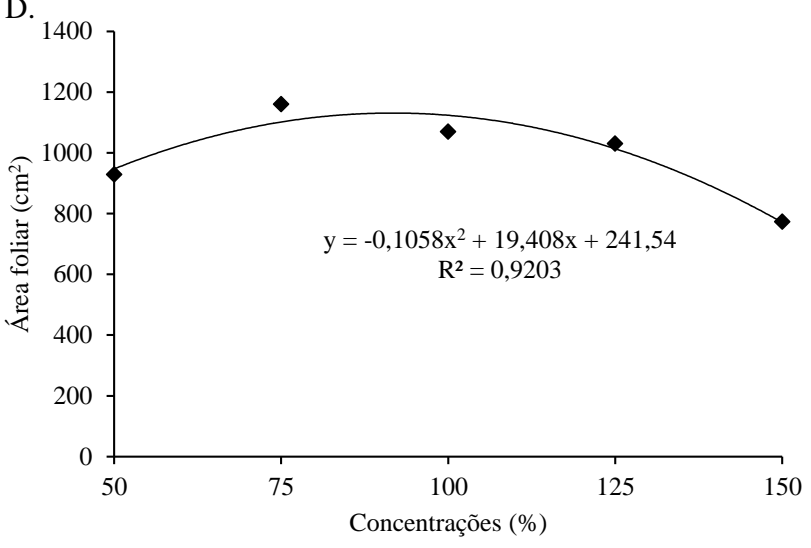

F.

$\diamond \mathrm{MSF} \diamond \mathrm{MSC} \triangle \mathrm{MSR} \triangle \mathrm{MST}$

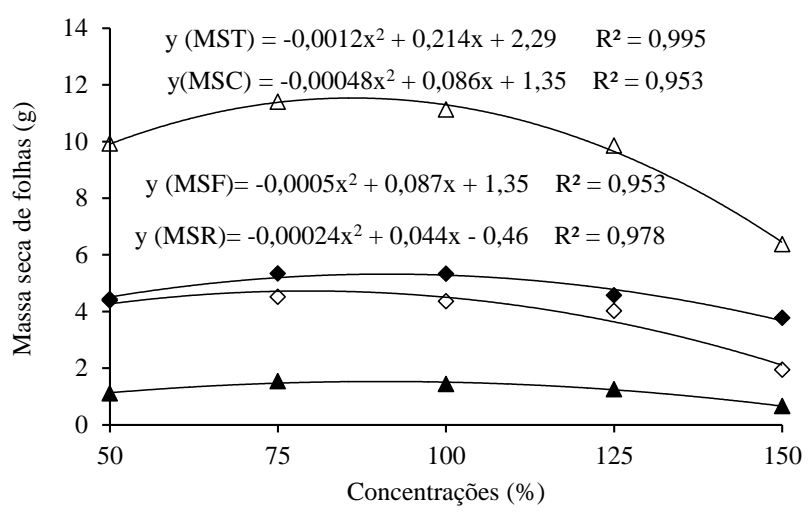

\section{Conclusões}

O cultivo de manjericão verde proporciona melhores produções quando são produzidas em fibra de coco fertirrigadas, utilizando solução nutritiva padrão recomendada para a produção hidropônica de folhosas.

\section{Referências}

BERTOLUCCI, S. K. V.; LAMEIRA, O. A.; PINTO, J. E. B. P. Guia das plantas medicinais. In. 
Lameira, O. A.; Pinto, J. E. B. P. (Ed.). Plantas medicinais: do cultivo, manipulação e uso à recomendação popular. Belém, PA: Embrapa Amazônia Oriental, 2008. Cap. 7. p.159-244

BIONE, M. A. A.; PAZ, V. P. S.; SILVA, F.; RIBAS, R. F.; SOARES, T. M. Crescimento e produção de manjericão em sistema hidropônico NFT sob salinidade. Revista Brasileira de Engenharia Agrícola e Ambiental, v.18, n.12, p.1228-1234, 2014.

FERNANDES, P.C.; FACANALI, R.; TEIXEIRA, J.P.F.; FURLANI, P.R.; MARQUES, M.O.M. Cultivo de manjericao em hidroponia e em diferentes substratos sob ambiente protegido. Horticultura Brasileira, Brasília, v.22, n.2, p.260-264, abril-junho 2004.

MAIA, S. S. S.; SILVA, R. C. P.; OLIVEIRA, F. A.; SILVA, O. M. P.; SILVA, A. C.; CANDIDO, W. S. Respostas de cultivares de manjericão à salinidade da água de irrigação. Revista Brasileira de Engenharia Agrícola e Ambiental, v.21, n.1, p.44-49, 2017.

MAY, A.; TANAKA, M.A.S.; SILVA, E.H.F.M.; PINHEIRO, M.Q. Ocorrência de cercosporiose em Ocimum basilicum L. Centro de horticultura - Plantas Aromáticas e Medicinais. 2008 . Disp on ível em: < http ://w ww.iac .sp.go v.br/Tecnologias/Aromaticas.htm>. Acesso em 29 abr. 2011.

OLIVEIRA, A. B.; HERNANDEZ, F. F. F.; ASSIS JÚNIOR, R. N. Absorção de nutrientes em mudas de berinjela cultivadas em pó de coco verde. Revista Caatinga, v. 22, p. 139-143, 2009.

OLIVEIRA, D. A.; FERNANDES, M. B.; RODRIGUES, J. J. V.; OLIVEIRA, R. A.; COSTA, F. G. B. Produção de mudas de pimentão e alface em diferentes combinações de substrato. Revista Verde, v. 3, n. 1, p. 133137, 2008.

OLIVEIRA, F. A.; MEDEIROS, J. F.; LINHARES, P. S. F.; ALVES, R. C.; MEDEIROS, A. M. A.; OLIVEIRA, M. K. T. Produção de mudas de pimenta fertirrigadas com diferentes soluções nutritivas. Horticultura Brasileira, v.32, p.458-463, 2014

PAGLIARINI, M. K.; BISCARO, G. A.; GORDIM, C. R. B.; SANTOS, A. M.; BRANDÃO NETO, J. F. Níveis de fertirrigação na avaliação das características morfologicas em mudas de pimenta malagueta. Irriga, v. 17, n. 1, p. 46-55, 2012. 